\title{
EL SUEÑO DE CALISTO Y LA TRADICION CELESTINESCA
}

\section{Ricardo Castells Duke University}

Casi quinientos años después de la primera edición conocida de Celestina, todavia no se han resuelto las muchas contradicciones inherentes en la interpretación de la escena inicial de la obra, un episodio que consiste en una conversación breve y enigmática entre Calisto y Melibea. No es de extrañar que existan problemas en la interpretación del comienzo de la obra, pues la escena se caracteriza por una localización irregular, un lenguaje complicado, alusiones curiosas y hasta heréticas, junto con un cambio repentino y difícilmente explicable en la actitud de Melibea ante Calisto. Frente a estas dificultades, la crítica, casi sin excepción, ha aceptado como verídicas las palabras del argumento del primer acto de la obra, las cuales indican que "Entrando Calisto una huerta empos dun falcon suyo, halló y a Melibea, de cuyo amor preso, començóle de hablar; de la qual rigorosamente despedido, fue para su casa muy sangustiado" (I, 
pág. 85). Rojas revelà en el prólogo de la Tragicomedia que los argumentos que aparecen en la Comedia de 1499 son la obra de los impresores, refiriéndose al taller del impresor burgalés Fadrique Alemán de Basilea. Rojas admite la posibilidad de aceptar los argumentos, pero indica claramente que éstos sólo representan una posible interpretación dentro de la contienda ya existente para entender el significado del libro:

Assi que quando diez personas se juntaren a oír esta comedia en quien quepa esta differencia de condiciones, como suele acaescer, ¿quién negará que aya contienda en cosa que de tantas maneras se entienda? Que aun los impressores han dado sus punturas, poniendo rúbricas o sumarios al principio de cada auto, narrando en breve lo que dentro contenía; una cosa bien escusada según los antiguos escriptores usaron. (81)

Si Rojas ni rechaza ni acepta la interpretación de los actos que aparecen en los argumentos, la critica moderna ha encontrado extensos inconvenientes con las palabras del impresor burgalés. Stephen Gilman (1956) ha notado que «if we as readers want to find out what La Celestina is really about, these argumentos are the last place to which we ought to turn» (213): Sin embargo, a pesar de reconocer la mala calidad de los argumentos, Gilman curiosamente excluye el argumento del primer acto de este juicio tan severo: «Unlike the first act, the quality of these argumentos-their performance of their descriptive function-is so inadequate that Rojas' disclaimer [in the Prólogo of the Tragicomedia] has generally been believed» (212). Sin embargo, el juicio de Gilman nos deja con la duda de por qué debemos aceptar el argumento del primer acto si se reconoce que estos argumentos claramente no forman un marco adecuado para la obra. La interpretación tradicional de la primera escena forma la base para numerosos estudios sobre el amor cortés y otros puntos claves en la comprensión de la obra, pero sospechamos que se acepta esta interpretación no porque sea totalmente adecuada, sino porque hasta el momento no se ha encontrado una alternativa más convincente.

Martín de Riquer (1957), consciente de la dificultad de leer una obra escrita por dos autores diferentes con argumentos escritos por un tercero, examina el primer acto de la obra sin tener en cuenta el 
argumento escrito posteriormente por los impresores. La idea de Riquer es de estudiar el primer acto en su forma primitiva para analizar la obra tal como la concibió el antiguo autor antes de que la alterara Rojas. Riquer llega a la conclusión de que el argumento es erróneo y que no cuadra bien con la acción de la escena en su forma original:

Si las leemos con ciudado y sin prejuicios, observaremos que las primeras palabras que se cruzan los dos jóvenes no revelan en modo alguno un encuentro casual, ya que Calisto afirma que ha hecho una serie de promesas...para conseguir de Dios que le otorgara el galardón de «este lugar alcançar»...Calisto, pese a la afirmación del argumento del acto primero, no parece que haya llegado a presencia de Melibea en pos de un halcón. En toda la escena el ave de caza no se menciona para nada, el joven no hace ni el más pequeño gesto que indique que va en su busca ni que la recoja y la doncella no alude ni tan sólo vagamente a un incidente de esta suerte: (384)

Para Riquer, el primer episodio del libro en su forma primitiva «no transcurria en el huerto de Melibea y no tenía nada que ver con la búsqueda de un halcón» (385). La idea del halcón no se presenta en Celestina hasta el segundo acto del libro en la conversación entre Calisto y Pármeno, y Riquer cree que no corresponde al concepto que tenia el antiguo autor del episodio inicial. Al manifestar Calisto su «secreto dolor» y «el servicio, sacrificio, devoción y obras pías que por este lugar alcançar yo tengo a Dios offrecido» ante Melibea (I, 86), la primera escena no puede ser un primer encuentro entre Calisto y Melibea. Riquer propone una iglesia como el lugar de la reunión entre los dos .jóvenes-algo parecido al punto de vista de Anna Krause (1953)-debido a las alusiones religiosas de la escena, que pudieran haber sido inspiradas en el ambiente religioso en que se encuentran los dos personajes. Riquer considera que Rojas creyó que el primer episodio tenía lugar en el huerto, pero que esta interpretación no respeta el sentido original del primer acto.

A. Rumeau (1966) acepta la idea de Riquer de que la primera escena no es la que menciona Pármeno en el segundo acto, ni la que describe el argumento del primer acto. Rumeau ve en la primera 
escena un segundo encuentro entre los dos jóvenes en el cual el ya enamorado Calisto le declara su amor a Melibea, y también admite la posibilidad de que este encuentro se haya realizado en una iglesia. W. D. Truesdell (1973) repite la labor de Riquer de leer la obra independientemente de los argumentos, y concluye que parte de la interpretación de Riquer es válida: «what was convincing about the Riquer arguments was not the placement of the scene within a church, but rather the proofs that it could not possibly have been in Melibea's garden» (264). Lo más significativo de la escena inicial para Truesdell es el hecho de que el antiguo autor no menciona ningún lugar específico para la plática entre Calisto y Melibea: «The author could only have been trying to indicate that this initial and allimportant scene took place nowhere, outside of conventional space, in unlocalized, 'abstract' space [without spatial and/or temporal concretization]» (265).

Truesdell hace hincapie del contenido herético de lo que dice el joven, y del sentido indefinido de las palabras: «[Calisto] asks the rhetorical question: '¿Quién vido en esta vida cuerpo glorificado de ningún hombre, como agora el mío?' The phrase 'cuerpo glorificado' is very telling. According to Catholic theology the saints enjoying beatific vision do so without the benefit of their earthly bodies» (268). Como la escena no se sitúa en el espacio y en el tiempo, Truesdell asevera que la conversación inicial ocurre «nowhere, outside of conventional space, in unlocalized, 'abstract' space. One must ask why the primitive author went to such pains to avoid the localization of Scene I, why he strove to create abstraction and universalization for the introduction of his work» (275).

A pesar de las ideas de Riquer, Rumeau y Truesdell, la critica todavia acepta la interpretación tradicional de la primera escena, como han hecho por ejemplo Maria Rosa Lida de Malkiel (1962), R. E. Barbera (1970), F. M. Weinberg (1971), Charles B. Faulhaber (1977) y Michael Solomon (1989). Sin embargo, al aceptar la interpretación tradicional de la primera escena, los críticos pasan por alto el hecho fundamental de que la continuación de Rojas indica claramente que el primer encuentro entre Calisto y Melibea ocurre antes de la primera escena. Esta realidad se nota por primera vez durante el primer día de la obra cuando Pármeno dice que el neblí se perdió en el jardín de Melibea «el otro dia». (II, 134). La misma estructura temporal se repite una $y$ otra vez en el libro, y se reafirma en el último acto 
cuando Melibea le dice a su padre-al comienzo del cuarto y último día de la Comedia-que «muchos días son passados...que penava por mi amor un cavallero que se llamava Calisto...» (XX, 333). ${ }^{1}$

1 Las otras veces que se repite la idea de que el primer encuentro entre Calisto y Melibea ocurre antes del comienzo de la obra son las siguientes:

1) Melibea: «Este (Calisto\} es el quel otro día me vido y començó a desvariar conmigo en razones, haziendo mucho del galán. Dirásle, buena vieja, que si pensó que ya era todo suyo y quedava por él el campo, porque holgué más de consentir sus necedades que castigar su yerro, quise más dexarle por loco que publicar su [grande] atrevimiento» $(\mathrm{V}, 162-3)$.

2) Calisto: «En sueños la veo tantas noches, que temo no me acontezca como a Alcibíades [o a Sócrates], que [el uno] soñó que se veya embuelto en el manto de su amiga y otra día matáronle...» (VI, 186).

3) Melibea: «Muchos y muchos dias son passados que esse noble cavallero me habló en amor; tanto me fue entonces su habla enojosa quanto después que tú me lo tornaste a nombrar, alegre» $(X, 245)$.

4) Lucrecia: «Señora, mucho antes de agora tengo sentida tu llaga y callado tu desseo; hame fuertemente dolido tu perdición. Quanto tú más me querias encobrir y celar el fuego que te quemava, tanto más sus llamas se manifestavan...» $(X, 247)$.

5) Calisto: «O quántos días antes de agora passados me fue venido esse pensamiento a mi coraçón, y por impossible le rechaçava de mi memoria...» (XII, 261).

6) Melibea: «...y aunque muchos dias he pugnado por lo dissimular, no he podido tanto que, en tornándome aquella mujer tu dulce nombre a la memoria, no descubriesse mi deseo y viniesse a este lugar...» (XII, 261). 
¿Será que Rojas cambió el sentido de la escena inicial como opina Riquer, o es que Rojas la interpretó de una manera que la crítica moderna no ha entendido? Para los críticos tradicionales-igual que para Riquer-las contradicciones que existen entre el argumento de los impresores y el contenido de la primera escena se deben al cambio de autor después del primer acto. Faulhaber, por ejemplo, escribe que

We have...to reconcile two sets of facts: Act I...presuppose[s] that Calisto is in love with Melibea before he speaks to her in the garden. The references in Acts II and IV, and the argumentos, imply that the hawk entered the garden by chance, that Calisto followed it, and that he fell in love with Melibea at first sight. In short, Act $I$ is at variance with the argumentos and the rest of the work. This discrepancy confirms the authorial difference between Act $I$ and the other acts, but it also testifies to Rojas' respect for the textual integrity of Act $I$. (446)

Aunque se puede hablar de la diferencia de autor entre el primer acto y el resto de la obra, jamás se explica por qué un escritor de la capacidad indiscutible de Rojas tendria que cambiar el sentido original de la primera escena para hacer la continuación del libro. En realidad lo que ha hecho la critica moderna es algo poco común en la historia de las letras hispánicas: le han dado prioridad al argumento escrito por un impresor extranjero o un aprendiz desconocido, sobre el texto que ha escrito Fernando de Rojas, un autor a quien todos reconocen como una de las figuras más importantes de la literatura española renacentista. Sin embargo, a pesar de las contradicciones implícitas en la crítica tradicional, los críticos heterodoxos tampoco han podido resolver el enigma del primer acto. Sí pueden sugerir que la primera escena no es un encuentro casual entre Calisto y Melibea, y que tampoco ocurre durante el primer día de la obra, pero estos críticos no han podido localizar el episodio inicial tan problemático, pues no se acepta que haya tenido lugar en una iglesia como opina Riquer, y a su vez es difícil admitir la idea de Truesdell de que ocurre en un lugar

7) Calisto: «Muy cierto es que la tristeza acarrea pensamiento y el mucho pensar impide el sueño, como a mí estos dias es acaecido con la desconfiança que tenia de la mayor gloria que ya poseo» (XIII, 276). 
abstracto e indefinido. Para cambiar la interpretación tradicional, hace falta mostrar dónde, cuándo y cómo se desarrolla este episodio, pero de una forma original y a la vez lógica y coherente. ${ }^{2}$

Miguel Garci-Gómez (1985) ha intentado resolver las contradicciones que existen el la interpretación del comienzo de Celestina, $\mathrm{y}$-como han hecho anteriormente Riquer $\mathrm{y}$ Truesdell-estudia el primer acto de la obra aparte del argumento del impresor. Garci-Gómez de nuevo afirma que el encuentro en el jardín de Melibea que describe Pármeno en el segundo acto tiene lugar antes de la escena inicial de la obra, debido a las repetidas referencias temporales en la continuación del libro hecha por Rojas. Garci-Gómez también indica que no sólo es Melibea la que parece desvanecerse de la escena inicial (y no Calisto), sino que la obra del antiguo autor no indica que Calisto haya salido de su cámara durante este episodio clave. Si la escena inicial no ocurre en el huerto de Melibea, y tampoco Calisto ha salido de su alcoba durante el primer episodio, entonces la única interpretación posible es que toda la escena ha sido un sueño de un Calisto ya enamorado:

La cámara, está claro, es el único lugar mencionado. Sempronio es el único personaje que acompañaba físicamente a Calisto. ¿Y Melibea? Calisto acababa de dialogar con ella. Pero ni la hemos visto allí, físicamente, ni hemos visto que saliera. Su presencia se desvaneció. Como se desvanecen las apariciones. Calisto, ¿quién lo duda?, habia tenido una aparición, una visión, un sueño. (14)

Esta interpretación es sin duda sorprendente, pero la visión de un Calisto soñador se repite una y otra vez a lo largo de la obra, de manera que esta posibilidad cuadra perfectamente con el carácter del

2 Miguel Marciales (1985) reconoce las dificultades textuales del primer episodio, pero a su vez of rece una posible explicación para el enigma de la conversación inicial entre Calisto y Melibea. Para Marciales, «todo problema desaparece si originariamente Melibea hubiera sido una mujer casada» (I, 84). Aunque admitimos la posibilidad de la tesis de Marciales, intentamos of recer otro punto de vista que cuadra mejor con el texto y con las tradiciones de la novela dramática española. 
joven protagonista. A la vez, la escena trazada por Garci-Gómez tiene un antecedente importante en el comienzo de la comedia humanística, el Paulus de Pier Paolo Vergerio, un parecido notado anteriormente por Menéndez Pelayo y Lida de Malkiel. Empero, Garci-Gómez sugiere que no es tanto un parecido como una clara repetición del episodio: "En ambas obras los jóvenes protagonistas se despiertan tras haber gozado de un sueño glorioso e increpan, en tono muy destemplado, a uno de los criados» $(17, \mathrm{n} 15)$. Finalmente, esta interpretación indica que Rojas entendia y respetaba la obra del antiguo autor, y que no habia ninguna contradicción temporal entre el primer acto y la continuación de la obra.

Sin embargo, para aceptar la tesis de Garci-Gómez de que el encuentro entre Calisto y Melibea no ha sido nada más que un sueño, es preciso mostrar que el lector de aquella época lo hubiera entendido como tal, y que el argumento inicial ha sido un error por parte de un impresor descuidado. Aunque le parezca extraño al lector moderno, la posible actitud soñolienta de Calisto no le extrañaria al lector renacentista por ser un tema común en la literatura amorosa de los siglos XV y XVI, como se ve en Cárcel de amor y también en la égloga II de Garcilaso. ${ }^{3}$ Empero, para mostrar que el episodio inicial de Celestina ha sido una visión o un sueño, habria que examinar las

3 En la égloga II, por ejemplo, Salicio le habla a Albanio cuando éste se levanta por la mañana entre el sueño y la realidad, algo parecido a lo que pudiera haber ocurrido en Celestina entre Sempronio y Calisto:

Albanio:

¿Es esto sueño, o ciertamente toco

la blanca mano? ¡Ah, sueño, estás burlando!

Yo estábate creyendo como loco...

Salicio:

Albanio, deja el llanto, qu'en oillo me aflijo.

Albanio:

¿Quién presente, 'sta a mi duelo?

Salicio:

Aquí está quien t’ayudará a sentillo.

$$
\text { (vv. 113-115 y 122-124, pág. 139) }
$$

Para la importancia del sueño en la literatura española anterior a Rojas, véase Harriet Goldberg, «The Dream Report as a Literary Device in Medieval Hispanic Literature,» Hispania 66 (1983): 21-31. 
novelas dialogadas que toman a Celestina como modelo y mostrar que los autores de este género interpretaban al episodio inicial de esta manera.

Un análisis de la tradición celestinesca en los siglos XVI y XVII revela que el sueño de Calisto no es sólo una posibilidad, sino que este sueño inicial es un patrón que se repite una y otra vez en la novela dialogada española por más de un siglo. Si bien los impresores de Celestina no pensaban que Calisto soñaba con Melibea al principio de la obra, los usos repetidos de este patrón sugieren que es probable que si lo hayan entendido de esa manera los escritores que hicieron una reescritura de la historia de Calisto y Melibea. ${ }^{5}$

Las primeras novelas dialogadas después de Celestina son las comedias Thebaida, Serafina e Hipólita, publicadas en Valencia en 1520 o 1521. La comedia Thebaida se escribio aparentemente entre 1504 y $1520,{ }^{6}$ pero a pesar de seguir algunas pautas de la obra de Rojas, no se caracteriza por el tono trágico y didáctico de Celestina. En la primera escena de la obra-en realidad el primer acto-, Berintho está despierto pero sufre mientras ve a Cantaflua en la imaginación:

...pues estoy tal que la imaginación y pensamiento un solo momento no se devierte a extraños actos, ni dexa de contemplar su tan immensa y extremada hermosura...y la gracia tan resplandeciente con que a todas las del mundo excede y sobrepuja. Y cuando ya algún tanto vaco me siento de la tal imaginación, quedo $\tan$ laso, quedo $\tan$ fatigado y tan sin acuerdo que hago harto en tornar poco a poco a cobrar aliento de nuevo, para con fuerça reziente tornar a emprender el fuego tan intolerable y tan agente en que por su causa a la

4 Aqui se entiende el sueño en su sentido más amplio, e incluye el soñar despierto, los delirios, los devaneos y las visiones.

5 Para dos estudios de la novela dramática española, véase Manéndez Pelayo (1915) y Heugas (1973).

6 Keith Whinnom, «Introduction,» La comedia Thebaida, págs. xvxvii y xxiii-xxviii. 
contina me estoy quemando; sin que su ravia y llama cruel un solo instante me dexe reposar. (9)

Berintho se encuentra en su habitación con los criados Menedemo, Galterio, Simaco y Aminthas, pero en la comedia queda claro que el protagonista no sale de la cama a lo largo de la primera cena:

Berintho. Bien dize Galterio. Acércate más, Menedemo. Y aun ambos os podéis hincar de rodillas en el estrado que está delante la cama, porque [yo] oiga bien lo que dixéredes... (13).

Berintho. $Y$ tú, Menedemo, pues ya es noche enciende velas y llégame la mesa aqui a la cama, y dame papel y escrivania, y siguiendo. el consejo del inspirado por spiritu prophético escriviré de mi espacio entretanto que Franquila viene. (30)

A pesar de estar despierto, Berintho está tan afligido por el amor que le cuesta trabajo distinguir entre la imaginación y la realidad, y por lo tanto indica que las cosas le vienen como en sueño: «Algo parece que se me va acordando, pero semeja al pensamiento haver visto todas estas cosas en sueños. Pero procede, [Menedemo,] y podrá ser que cayese algún tanto en la cuenta» (22).

La tercera, Franquila, llega a la casa de Berintho en la escena cuarta de la comedia, pero ella se queda «a los pies de la cama» observando el delirio de Berintho sin que éste se dé cuenta de la presencia de ella:

Pero entrando vi que Berintho estava hablando a bozes consigo-y ha dicho tantos desatinos que no lo podriedes pensar-, y porque con mi vista tan inopinada no fuesse de un extremo a otro con el amor que me tiene, y la súbita mudança fuese causa de algún inconveniente desastrado, tove por mejor esperarme un poco que no con $\mathrm{mi}$ entrada improvisa poner en condición su salud.... Que le dexemos, specialmente hasta que acabe de devanear. (53)

Berintho recita romances amorosos en esta escena pero todavia sin darse cuenta que Franquila y los criados lo están observando. No es 
hasta que el grupo ve que el mozo está «ya reposado, y [que] ninguna cosa habla» (65) que lo pueden sacar del devaneo que padece.

Berintho no es el único amante de la comedia Thebaida que parece vivir entre el sueño, el delirio y la realidad. Cantaflua aparece por primera vez en la obra en la cama y en medio de un lamento parecido al de Berintho, y la muchacha tampoco se da cuenta de que hay otras personas en su habitación. Sin embargo, cuando su criada Claudia se entera que la tercera Franquila trae una carta de Berintho, la sirvienta en seguida saca a la muchacha del sueño: «O cuitada! iY por qué no lo havias dicho antes [, Franquila]? $Y$ hoviéramosla reçucitado aunque estoviera muerta. Espera, espera, y verás por esperiencia lo que digo. Señora, señora, que está aquí Franquila y os trae una carta de Berintho, y ha dos horas que espera aqui» (103).

Franquila luego vuelve a la casa de Berintho en la escena novena con la respuesta de Cantaflua, pero el joven protagonista todavía sigue en la cama con el mismo delirio de antes. Se despierta Berintho para oír las palabras de Franquila, pero aún le cuesta trabajo distinguir entre la imaginación y la realidad: «¿Qué es lo que dizes a Menedemo [, Franquila]? Que todo cuanto me has dicho tengo entendido, pero aún pienso que estoy durmiendo» (136). Al fin de la plática entre Berintho y Franquila, el mozo siente la necesidad de volver a dormir, como si ésta fuera la actitud típica del enamorado afligido: "Ya es tarde, y yo tengo gana de reposar un rato» (150).

El amante que sufre entre devaneos y sueños no es sólo una idea repetida varias veces en $L a$ comedia Thebaida, sino que también hay que recordar que los dos amantes se presentan por primera vez en la obra de esta manera, lo mismo que pudiera haber ocurrido con Calisto en Celestina. El tema es tan común en Thebaida que cuando los criados Aminthas y Claudia se enamoran, pronto se encuentran en la misma actitud sonámbula de sus amos (189-190; 193-195). La misma idea se ve al principio de la Comedia Serafina, también del año 1520 ó 1521. En la primera escena de la obra los criados Pinardo, Cratino, Popilia y Davo hablan del amor que siente su amo Evandro por la casada pero todavía virgen Serafina, y Cratino comenta:

La ymaginación en la cosa siempre suele refrescar las llagas, esto de una parte; y también ver a la clara la voluntad de Serafina an dado causa a que el viejo dolor, cobrando aliento de nuevo, con rezientes fuerças 
a tornado a lo atormentar de tal manera que toda esta noche ni él adormió ni a mí dexó pegar los ojos. (12)

El amante Evandro, igual que Berintho, aparece por primera vez en la obra en la cama atormentado por el delirio y el sueño, y también se pone a recitar romances amorosos. Esta situación no termina hasta que la criada Popilia les dice a los mozos que entren al cuarto para sacar a Evandro de sus devaneos. Hay que notar que los criados salen de la sala-lo mismo que hace Sempronio en el primer acto de Celestina-de manera que este episodio parece seguir el patrón de Celestina en varios aspectos:

Evandro. Moços, moços, ¿estáys ahi?

Cratino. A la puerta de la sala estávamos. ¿Qué mandas, señor?

Evandro. ¡O cómo me abraso en el fuego que veo a la clara proceder de los ojos de Serafina!.... ¡O cómo la misma discordia está predominando en mi pecho! ¡O cómo la confisión me aconpaña! (19)

Igual que para Calisto y Berintho, el delirio es un estado normal para Evandro, como observa el criado Penardo en una conversación con Popilia: «Entretanto que ese ciego de razón y falto de entendimiento está devaneando como suele, anda acá a tu cámera...» (26).

Aunque estas comedias valencianas tienen un parecido evidente con Celestina, lo que es netamente el género celestinesco empieza con la Segunda Comedia de Celestina de Feliciano da Silva, cuya primera edición es del año 1534. La Segunda Celestina narra los amores del caballero Felides con la joven Polandria, pero esta vez con la misma Celestina de tercera. En esta versión de la historia de Celestina, la alcahueta no ha muerto a manos de Pármeno y Sempronio como en la obra de Rojas, sino resulta que ella ha aparentado la muerte para vengarse de los dos criados de Calisto y para escaparse de la justicia.

La primera escena de la Segunda Celestina comienza de nuevo con el sufrimiento del joven amante, Felides pero el protagonista está despierto y hasta muestra cierto sentido del humor sobre su situación. Felides llama a sus criados Sigeril y Pandulfo en esta escena inicial, pero al principio de la escena no está claro-por lo menos para el lector moderno-dónde tiene lugar la acción. Sin embargo, las últimas 
palabras de la escena primera indican que Félides no ha dormido toda la noche y que la escena entera se ha desarrollado en su habitación, como si el autor esperara que el lector de aquella época reconociera el lugar de la escena desde su principio:

Sigeril. ...y en tanto reposa tú, señor, que no has dormido esta noche; e yo iré a dar priesa a este panfarrón [de Pandulfo], no se vaya todo en fieros e palabras su hecho.

Felides. Ansi lo haz, y ve con Dios e ciérrame esta puerta. (36)

La Tercera parte de la Tragicomedia de Celestina (1536) es obra de Gaspar Gómez de Toledo, y pretende ser una continuación de la Segunda Celestina de Fernando de Silva, a quien Gómez le dedica la obra. El primer auto de la Tercera Celestina ocurre el dia después de la última escena de la Segunda Celestina. Felides y Polandria pasaron la noche anterior juntos y se han llegado a desposar al final de la Segunda Celestina, pero aún les falta el permiso de los padres de Polandria para celebrar bodas públicas. En la Tercera Celestina, Felides aparece en el primer auto de la obra al despertarse por la mañana, pero con «el sueño, tan suave para mi contemplación y tanto descanso para mi atribulado coraçón» (78) de que ha pasado la noche en la huerta de Polandria junto con ella. O sea, que la idea del sueño inicial del protagonista es tan aceptado en el género de la novela dialogada que Felides cree que ha soñado lo que ha ocurrido en realidad: "Es vn sueño que, avnque es increyble, me causa tanta delectación que affirmo las ymaginaciones que Ouidio escriue de Teseo con Adriena no le diessen la tercia parte désta que tengo... ¡O cómo soy insensato, pues con el deleyte de mi sueño comparo otro ninguno que por la misma forma acontesciesse!» (79). De nuevo el comienzo de la obra es en la alcoba del protagonista, con éste en la cama en medio de sus devaneos mientras el criado se queda afuera de la habitación:

Felides. Sigeril, ¿estás ay?

Sigeril. Ansi te puedes secar que yo entre en esta hora, que primero quiero, avnque me duela la cabeça de oyrte, escuchar tus deuaneos. (80) 
En otras novelas celestinescas posteriores, el protagonista no aparece por primera vez entre sueños, pero pronto lo vemos en una actitud parecida. La Tragedia policiana (1547) del Bachiller Sabastián Fernández presenta la historia de Claudina, la madre de Pármeno y la comadre de Celestina. En el primer acto de la obra, el protagonista Policiano está despierto cuando llama a sus criados, pero en el tercer acto-cuando los criados vuelven a la casa por la mañana después de estar fuera toda la noche-vemos al amo en la misma actitud soñolienta de los demás amantes celestinescos:

Solino. ¿Qué haze nuestro amo? ¿Ha pedido de vestir?

Silvanico. Aý está en esta cama que no haze más ruydo que vn muerto.... Casa es de locos ésta por la fe en que creo. El amo troba, los moços van a rondar, pues algún día no ha poder que nos sea la mia.

Salucio. ¿Troba por auentura el triste de Policiano?

Silvanico. Doy al diablo si otra cosa haze sino dezir disparates; llora como niño, da bozes como loco, no sé qué se tiene.

Policiano. Oyes, paje.

Silvanico. Señor.

Policiano. ¿Es de dia?

Silvanico. E muy gran parte passada.

Policiano. O desdichado de mi, que después que mi coraçón se escuresció, no sé qué : cosa es ver claridad. Yo no entiendo quándo amanesce, sino a caso no es por oydas. (7)

La Comedia Selvagia (1554) de Alonso de Villegas Selvago es algo diferente al resto de la tradición celestinesca porque presenta a dos protagonistas, Flerinardo y Selvago. Los dos protagonistas hablan del amor deshonesto y del amor casto en el primer acto, pero el tercer acto presenta a Flerinardo cuando se levanta por la mañana después de un sueño, y en este sueño conversa con la amada Rosiana casi de la misma forma que parece hacer Calisto en Celestina: 
No otro sino que habiendo toda la noche gastado en diversos pensamientos, ya cerca de la aurora me vino un profundo sueño, en el qual cosas maravillosas, aunque bien oscuras, me fueron presentadas (...) la señora que en captividad mi corazón tiene puesto, se me demostró con tanta ira y enojo contra mi, quanta hermosura y beldad con para con todos tiene; (...) Habiendo, pues, algún tanto mis muchos miedos considerado, con algo más apacible rostro, desta manera me habló. "iOh tú, que por tan mi verdadero captivo te has mostrado, ...como a la verdad eres digno a que rigurosamente mi crueldad contra tu locura proceda, pues no solamente violaste mi limpieza con tu dañado pensamiento, mas, aun poniendo mi honra en condición, te jactas y vanaglorias a todos manifestarlo.» (57)

Pero como Fleriano tiene honradas intenciones, le explica a la dama sus intenciones y la dama cambia de tono:

Entonces ella, con rostro amoroso y apacible, me respondió en esta manera: «Por ver tu mucha contrición, y que aun el pecado no se puso por obra, yo quiero por ahora perdonarte...» Pues dichas estas palabras, súbitamente de mi vista se desapareció, y yo de aquel profundo sueño fui libre. (58-59)

Es importante ver que el autor Alonso de Villegas Selvago-todavía bachiller como Rojas pero después teólogo en la Universidad de Salamanca-repite el cambio de carácter de Melibea, pero esta vez es de la furia a la tranquilidad, para alabar de esa manera el amor honesto que es el tema principal de esta comedia. Sin embargo, vemos en este sueño la misma conversación entre los dos amantes y la desaparición repentina de la amada, y después el protagonista que se despierta del sueño una vez que se desvanece la visión de ella.

No es la única vez en la obra que se presenta al amante entre sueños, pues Selvago hace lo mismo la mañana después de conocer a su amada Isabel: « ¿Válame el poderoso Dios! ¿Qué será esto? ¿Por ventura no estaba yo agora en el reino de mi señora, lleno y de su gracia y gozando de su soberana gloria? Pues, ¿cómo me hallo en mi 
lecho? Sin duda que con algún fingido ensueño he sido engañado; bien será me certifique de segunda persona. ¡Mozos, mozos!» (134). Selvago, igual que otros protagonistas celestinescos, se levanta de la cama y pronto está tocando el laúd y cantando romances amorosos.

El ejemplo más tardío de la tradición celestinesca es la novela dialogada La Dorotea de Lope de Vega, publicada en Madrid en 1632. El protagonista don .Fernando no sale en la obra hasta la cuarta escena del primer acto, pero de nuevo el galán aparece por primera vez en su cámara junto a su criado en el momento de levantarse por la mañana. Siguiendo la tradición ya establecida en las novelas dialogadas anteriores, don Fernando está molesto por un sueño, lo cual se revela en sus primeras palabras con su criado Julio:

Julio. Con poca gracia te levantas.

Fernando. Mil desasosiegos he tenido esta noche.

Julio. ¿No has dormido?

Fernando. Poco y con mil congojas.

Julio. Del calor serían.

Fernando. No, sino del primer sueño.

Julio. ¿Qué soñabas?

Fernando. Una confusión de cosas. (90)

Ésta no ha sido un sueño común y corriente, sino una pesadilla en la cual Dorotea y su criada Celia se bajan cargadas de oro de un barco americano, pero al bajarse del navío han dejado a Fernando solo sin dirigirle la palabra. El sueño alude a las riquezas del indiano don Bela, otro pretendiente de Dorotea, pero este rechazo de Dorotea podria ser una reescritura del rechazo de Melibea en el sueño al comienzo de Celestina. Aunque la escena no es identica, hay elementos parecidos entre el comportamiento de don Fernando y el de Calisto. Desde luego tienen el mismo estado de ánimo al levantarse por la mañana, aparentemente por haber tenido un sueño parecido. Fernando también canta romances amorosos y más tarde intenta encerrarse en la oscuridad de su cámara igual que hace Calisto: «Muerto soy, Julio. Cierra todas las ventanas, no entre luz a mis ojos, pues se va para siempre la que lo fue de mi alma» (111). 
Aunque no todas las comedias celestinescas tienen el mismo comienzo, desde luego se nota que el protagonista aparece por primera vez entre sueños y devaneos en las obras citadas. A la vez, la idea del sueño parece asociarse tanto con el género de la novela dialogada que Pedro Hurtado de la Vera usa esta forma literaria para escribir la alegoría la Doleria del sueño del mundo (1572), donde la obra entera es un sueño. El gran parecido que existe en la presentación inicial del galán enamorado en la Comedia Thebaida, la Comedia Serafina, la Segunda Celestina, la Tercera Celestina, La Dorotea, la Tragedia Policiana y la Comedia Selvagia sugiere la posibilidad que todas partan de un mismo patrón. Parece que estos autores que continuaron la tradición celestinesca vieron a un Calisto entre sueños al comienzo de Celestina, y por este motivo hicieron sus obras con este modelo en mente. Aunque el parecido que existe en obras posteriores no nos permite establecer la intención de Rojas o del antiguo autor al empezar la obra, of rece la posibilidad de que este sueño fuera un lugar común para los lectores de la época, y que en aquel entonces se reconociera que el primer acto de Celestina empezaba en la cámara de un Calisto sonámbulo.

Mientras las novelas dramáticas posteriores sugieren la idea del sueño para la escena inicial de Celestina, el estudio del primer acto de la obra revela que el sueño cabe perfectamente dentro del mundo literario creado por el antiguo autor. La idea del sueño logra localizar la acción en un sitio definido y lógico de acuerdo con la primera conversación entre Calisto y Sempronio. Las palabras de los dos personajes indican que Calisto acaba de salir de su alcoba y que se acaba de despertar- «Anda, anda, malvado [Sempronio]!, abre la cámara y endereça la cama.» (I, 88)-porque Calisto se levanta en ese momento y está molesto por lo que ha soñado. Hasta las mismas palabras de Calisto en la primera escena sugieren la posibilidad de que está observando una imagen irreal, pues todas las referencias indican que el episodio es una visión y no un encuentro verdadero:

En esto veo, Melibea, la grandeza de Dios.... En dar poder a natura que de tan perfecta hermosura te dotasse, y hazer a mi, inmérito, tanta merced que verte alcançasse, y en tan conveniente lugar (...) ¿Quién vido en esta vida cuerpo glorificado de ningún hombre como agora el mio? Por cierto, los gloriosos santos que se deleytan en la visión divina no gozan más que yo agora 
en el acatamiento tuyo. Mas, o triste, que en este deferimos, que ellos puramente se glorifican sin temor de caer de tal bienadventurança, y yo, misto, me alegro con recelo del esquivo tormento que tu absencia me ha de causar. (nuestro énfasis; I, 85-86)

Calisto emplea el verbo ver tres veces, y también menciona la idea de una visión o un acatamiento, pues parece que el mundo físico no cabe en este lenguaje aparentemente creado por la subconsciencia. Todo parece estar muy bien ligado a la interpretación de Truesdell que la alusión al cuerpo glorificado se refiere a una experiencia extracorporal. El único elemento lógico en las palabras de Calisto es la referencia a la ausencia de Melibea porque el galán reconoce en el sueño que esta visión de su amada no se podrá mantener cuando se despierte. Por eso, después que Calisto se levanta, cierra la ventana e intenta entrar al mundo de «la tiniebla» y «la ceguedad» (I, 88), pues si Melibea ha sido una visión, la oscuridad y la ceguera la pueden borrar de la memoria. El problema que padece no es un rechazo de Melibea, sino los «tristes pensamientos» después del sueño, y Calisto tiene la oscuridad como el remedio posible a su dolor (I, 88).

Aparte del intento del antiguo autor en el primer acto, la continuación de la obra hecha por Rojas subraya la importancia de los sueños y los devaneos de Calisto, de manera que también hay amplios indicios dentro de la Tragicomedia para sostener la idea del sueño inicial. Al principio del segundo auto-el primero que escribe Rojas-, el autor subraya este carácter sonámbulo y visionario de Calisto. Después de la partida de Celestina en el primer acto, Sempronio le aconseja a su amo que vuelva a la cama y que cuente con la mediación de los demás, pues entiende que Calisto no puede actuar solo y que la cama es el ambiente normal para él: «de mi consejo tórnate a la cámara y reposa, pues que tu negocio en tales manos está depositado» (II, 131). Sempronio no quiere dejar solo a su amo en parte porque «tu temor me aquexa» y porque «en viéndote solo, dizes desvaríos de hombre sin seso, sospirando, gemiendo, maltrobando, holgando con lo escuro, desseando soledad, buscando nuevos modos de pensativo tormento» (II, 132). Sin embargo, Calisto responde que no puede dejar este mundo imaginario pues para él es un estado natural y agradable: "¿Cómo, simple, no sabes que alivia la pena llorar la causa? ¿jQuánto es dulce a los tristes quexar su passión? ¿Quánto descanso traen consigo los quebrantados sospiros?» 
(II, 132). Calisto por fin acepta que no debe quedarse solo y que Pármeno lo debe acompañar, pero sigue tan confundido que no se da cuenta que Pármeno está a su lado:

Pármeno. Aquí estoy señor.

Calisto. Yo no, pues no te veya (II, 133).

En el sexto acto, Calisto indica que siempre sueña con Melibea, y que se encuentra turbado por estas visiones: «En sueños la veo tantas noches que temo no me acontezca como a Alcibiades [o a Sócrates], que [el uno] soñó que se veya embuelto en el manto de su amigo y otro día matáronle...» (VI, 186). Más adelante, en el octavo acto, Pármeno vuelve a casa por la mañana después de pasar la noche con Areúsa, y de nuevo Calisto está en la cama soñando con Melibea, lo mismo que parece haber hecho el dia anterior en el primer acto de la obra. Como dice Sempronio,

Allí está tendido [Calisto] en el strado cabe la cama donde le dexaste anoche, que ni ha dormido ni está despierto. Si allá entro ronca; si me salgo, canta o devanea. No le tomo tiento, si con aquello pena o descansa. (VIII, 217)

Este episodio es casi un reflejo fiel del primer acto, pues Calisto está trovando y "devaneando entre sueños» en su habitación (VIII, 218), y pronto llama a los mozos de la sala para que lo atiendan. Calisto no sabe si es de día o de noche cuando piensa en Melibea y les tiene que preguntar a Pármeno y Sempronio para enterarse de la realidad que lo rodea:

Calisto. ¿Es muy noche? ¿Es hora de acostar?

Pármeno. Mas ya es, señor, tarde para levantar.

Calisto. ¿Qué dizes, loco; toda la noche es passada?

Pármeno. Y aun harta parte del día. (VIII, 219)

A medida que se va desarrollando la novela, Calisto entra cada vez más en este mundo de sueños mientras su amor compulsivo hacia Melibea lo va consumiendo. Una vez que alcanza el amor aparentemente imposible de Melibea, se desliga casi completamente de la realidad externa y vive exclusivamente por este amor, bien sea de noche en el huerto de Melibea o de día en sueños en su propia 
habitación. Después de la muerte de Sempronio y Pármeno en el acto doce, Calisto vuelve a su habitación en el acto catorce después de pasar la noche con Melibea y conversa con un juez imaginario sobre estas muertes. Es importante notar que aquí empiezan los actos intercalados de la Tragicomedia, y que casi lo primero que hace Rojas al ampliar la Comedia es darle énfasis de nuevo al carácter sonámbulo de Calisto.

Cuando Calisto se da.cuenta de que la conversación con el juez es una visión-«Pero, ¿qué digo; con quién hablo; estoy en mi seso? ¿Qué es esto, Calisto; soñavas; duermes o velas; estás en pie o acostado? Cata que estás en tu cámara» (XIV, 290)-no quiere volver a la realidad sino a los sueños de su nuevo amor para revivir en la mente los momentos y las conversaciones que tuvo con Melibea. Han muerto Sempronio y Pármeno, los dos contactos principales que tenía Calisto con la realidad, de manera que el joven amante le puede dar rienda suelta a este mundo imaginario casi sin preocuparse por cualquier realidad que no sea Melibea:

Pero tú, dulce ymaginación, tú que puedes me acorre; trae a mi fantasía la presencia angélica de aquella ymagen luziente; buelve a mis oydos el suave son de sus palabras, aquellos desvíos sin gana, aquel «apártate allá, señor, no llegues a mí,» aquel «no seas descortés» que con sus rubicundos labrios vía asonar; aquel «no quieras mi perdición» que de rato en rato proponia; aquellos amorosos abraços entre palabra y palabra...» (XIV, 292-293)

Melibea le vuelve a hablar a Calisto en su imaginación como en la primera escena de la obra, pero ahora en una mezcla de sueño y realidad, como se verá después al comienzo de la Tercera Celestina.

Tanto en la primera intervención de Rojas en el segundo acto de Celestina, como en la ampliación del libro en el acto catorce de la Tragicomedia, lo primero que hace Rojas al continuar la obra es hacer hincapie a la tendencia de Calisto de vivir en medio de sus sueños. La labor de Rojas sugiere que él mismo vio a un Calisto entre sueños en la primera escena del primer acto, y que intentó seguir este modelo 
creado anteriormente por el antiguo autor. ${ }^{7}$ No es de extrañar entonces que los demás escritores del género celestinesco hayan seguido este patrón cuando desarrollaron sus propios protagonistas celestinescos, pues no hacen sino repitir la misma actividad creadora de Rojas. ${ }^{8}$ Más que un personaje paródico, Calisto es un personaje ficticio que inventa su propia realidad amorosa en la soledad de su cámara a partir de la primera escena de la obra, y la única vez que sale por completo de este mundo inventado, tropieza literalmente con la realidad y muere fuera de la casa de Pleberio.

La interpretación que propone Garci-Gómez para el comienzo de Celestina nos puede sorprender a primera vista, pero es la única interpretación hasta el momento que cuadra con la personalidad de Calisto, y que a la vez reconoce la capacidad creadora de Rojas y la unidad temática de la obra. Resuelve las aparentes contradicciones entre la primera escena y la continuación de la obra hecha por Rojas, y deja como el único elemento discorde el argumento escrito por los impresores de 1499. También tiene un vinculo directo con la tradición celestinesca de la novela española, mostrando de esta manera que la idea del sueño inicial se aceptaba plenamente en la España de los siglos XV y XVI.

7 Es muy lógico que Rojas haya entendido el sueño de Calisto en la obra del antiguo autor si recordamos la visión que nos da de su propia actitud en «El autor a un su amigo»: «...asaz vezes retraydo en $\mathrm{mi}$ cámara, acostado sobre mi propia mano, echando mis sentidos por ventores y my juyzio a bolar» (69).

8 Heugas ha comentado que, «Quant à la démarche de l'imitation, à la technique du démarquage, le deuxième auteur de La Célestine, Fernando de Rojas, avait donné le ton à ses futurs imitateurs, en adoptant vis-à-vis de la Célestine primitive une attitude absolument identique à celle que ses imitateurs adopteront vis-à-vis de sa propre création. Il s'est approprié des situations, des personnages avec leur caractère particulier, les rapports entre ces personnages, leur style enfin» (97). 


\section{OBRAS CITADAS}

Anónimo. La comedia llamada Serafina, ed. Glen F. Dille (Carbondale and Edwardsville: Southern Illinois University Press, 1979).

Barbera, R. E. «Medieval Iconography in La Celestina,» Romanic Review 61 (1970): 5-13.

Faulhaber, Charles B. «The Hawk in Melibea's Garden,» Hispanic Review 45 (1977): 435-450.

Fernández, Sabastián. Tragedia Policiana (Madrid: NBAE, 1910, vol. XIV).

Garci-Gómez, Miguel. «El sueño de Calisto,» Celestinesca 9, i (May, 1985): 11-22.

Garcilaso de la Vega. Poesias castellanas completas, ed. Elias Rivers (Madrid: Castalia, 1987).

Gilman, Stephen. The Art of 'La Celestina' (Madison: University of Wisconsin Press, 1956).

Gómez de Toledo, Gaspar. Tercera parte de la tragicomedia de Celestina, ed. M. E. Barrick (Philadelphia: University of Pennsylvania Press, 1973).

Heugas, Pierre. "La Célestine» et sa descendance directe (Burdeos: Institut d'Études Ibériques et Ibéro-Américains, 1973).

Krause, Anna. «Deciphering the Epistle-Preface to the Comedia de Calisto y Melibea,» Romanic Review 44 (1953): 89-101.

Lida de Malkiel, María Rosa. La originalidad artistica de "La Celestina» (Buenos Aires: EUDEBA, 1962; 1970).

Marciales, Miguel, editor. Celestina: Tragicomedia de Calisto y Melibea. Tomo I: Introducción al cuidado de Brian Dutton y Joseph T. Snow, Illinois Medieval Monographs, 1. (Urbana y Chicago: University of Illinois Press, 1985).

Menéndez Pelayo, Marcelino. Origenes de la novela (Madrid: NBAE, 1915). 
Riquer, Martín de. «Fernando de Rojas y La Celestina,» Revista de filologia española 41 (1957): 373-395.

Rojas, Fernando de. La Celestina, Ed. Dorothy S. Severin (Madrid: Cátedra, 1987).

Rumeau, A. «Introduction à Célestine: '...una cosa bien escusada...," Les Langues Neo-latines 60, núm. 176 (1966): 1-26.

Silva, Feliciano de. Segunda comedia de Celestina, Ed. I. Chamorro (Madrid: Editorial Ciencia Nueva, 1968).

Solomon, Michael. «Calisto's Ailment: Bitextual Diagnostics and Parody in Celestina,» Revista de estudios hispánicos 23 (1989): 41-64.

Truesdell, W. D. "The Hortus Conclusus Tradition, and the Implications of its Absence in the Celestina,» Kentucky Romance Quarterly 20 (1973): 257-277.

Vega Carpio, Lope de. La Dorotea, ed. Edwin S. Morby (Madrid: Castalia, 1987).

Villegas Selvago, Alonso de. La comedia llamada Selvagia (Madrid: Colección de Libros raros o curiosos, 1873, vol. V).

Weinberg, F. M. "Aspects of Symbolism in La Celestina,» MLN 86 (1971): $136-153$. 

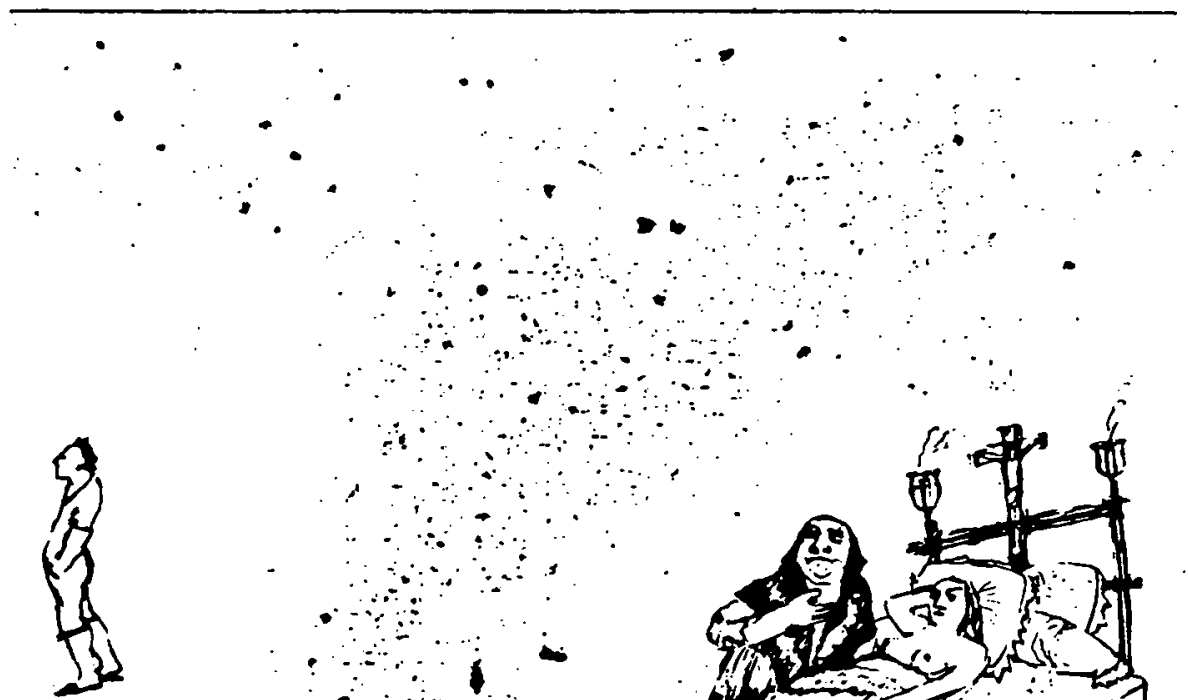

CEESTIKA DOES A DEAL WMA AREYA

Acto DII. PAMEla hoviard 